\title{
A Meta-Theory for Understanding Information Systems Within Sociotechnical Systems
}

\author{
ROBERT P. BOSTROM, SAURABH GUPTA, AND \\ DOMINIC THOMAS
}

Robert P. Bostrom is the L. Edmund Rast Professor of Business at the University of Georgia. He teaches in the MIS area. He is also President of Bostrom \& Associates, a training and consulting company focusing on facilitation and the effective integration of people and technology. Dr. Bostrom holds a B.A. in Chemistry and MBA from Michigan State University, an M.S. in Computer Science from SUNY at Albany, and a $\mathrm{Ph} . \mathrm{D}$. in MIS from the University of Minnesota. In addition to numerous publications in leading academic and practitioner journals, he has extensive consulting and training experience in the areas of MIS management and design, organizational development, leadership, facilitation, business process management, and digital collaboration. His current research interests focus on high-performing individuals, facilitation, business process management systems, digital collaboration, technology-supported learning, and the effective design of organizations via integrating human and technological components.

Saurabh Gupta is an Assistant Professor in the Coggin School of Business at the University of North Florida. He teaches in the MIS area. He has work experience in the field of knowledge management, system design, and enterprise resource planning implementation. Dr. Gupta holds a Ph.D. from the University of Georgia, a B.B.A. from Gujarat University, India, a Postgraduate Diploma in Management from Nirma Institute of Management, India, and an MBA from the University of Georgia. His current research interests are end-user training, technology-supported learning, knowledge management, and adoption of complex technology. His research has been published in the International Journal of Knowledge and Learning and Knowledge Management $\&$ Practice, with a forthcoming article in the Journal of the AIS.

Dominic Thomas is a Visiting Assistant Professor of Information Systems at Emory University's Goizueta Business School. He holds a Ph.D. in MIS from the University of Georgia (2005), a B.A. in English and American Literature from Brandeis University (1994), and has foreign language certifications in Russian, Nepalese, and Japanese. His research interests focus on innovating and improving organizational work systems, particularly through new information and communications technologies. His scholarship is informed by professional experience in international development and education systems design as well as prior assessments of global business systems. His articles have appeared in the Communications of the ACM, Communications of the AIS, and Information Systems Management, in addition to articles in journals in other fields and a forthcoming work in MIS Quarterly. 
ABSTRACT: Information systems (IS) research often attempts to examine and explain how technology leads to outcomes through usage of IS. Although extensive research in this area has resulted in a significant number of theories, limited work has been done on integrating these theories. This paper presents adaptive structuration theory (AST) as a meta-theory for examining IS within an organizational context. The two main contributions of the paper are an understanding of meta-theory's role in IS and building a case for using AST as a meta-theory to (1) provide an overarching perspective for understanding and integrating existing literature and theories, (2) provide a template and set of guidelines for creating better context-specific IS models and theories, and (3) provide a deeper understanding of a theory. Along with discussion of the contributions, we provide examples to guide researchers in applying AST as a meta-theory.

KEY WORDS AND PHRASES: adaptive structuration theory, conceptual model, meta-theory, technology-mediated learning, virtual teams.

THE ROLE OF INFORMATION SYSTEMS (IS) INTERVENTIONS in organizational change, especially as vehicles of enhanced business and managerial efficiency, has been a source of a large investment of time and money in organizations and a hot research topic. IS researchers have often struggled to produce a coherent generalizable understanding of IS in organizations, in part due to either focusing too much on technology at the expense of social elements of IS [51] or failing to adequately address the technical role of technology as an artifact [13]. A large amount of research points to this longtime research lack of integrated focus on both the social and technical subsystems in an organizational work system [14, 63, 67].

A work system is a system in which human participants and technology perform processes to produce products or services for internal or external customers [4]. Example work systems include a sales department, a commercial loan process, a systems development team, and a university. Sociotechnical systems (STS) theories view any organizational work system as consisting of social and technical subsystems, interacting with and influencing each other. As such, they offer a potential solution for the need in IS for more integrated theories. In STS theories, the technical subsystem consists of the business processes and the technologies (IS, machines, techniques, etc.) used to perform those processes. The technical subsystem transforms the system inputs into outputs in a way that enhances the overall performance of the organizational work system. The social subsystem is composed of the individuals and the knowledge, skills, attitudes, values, and needs they bring to the work environment, as well as the reward system and authority structures that exist in the organization. The social subsystem integrates into the technical system to help perform the transformation. STS theories argue that desired results can only be achieved if the interdependency of these subsystems is explicitly recognized and addressed.

STS models for organizational intervention and improvement have a long history in European management practice and research. Meanwhile, many North American 
IS studies produce theories that focus on a smaller number of STS constructs, often addressing either the technical or social subsystems in isolation, that only explain/ predict empirical results in a narrow context [23]. The accumulated STS literature shows marked improvement for effective change, easier worker transitions, and improved productivity over either a technical or a social view alone; but it also presents IS researchers and practitioners with daunting complexity [4, 5, 81, 118].

IS researchers have recognized the challenge of integrating IS findings in narrow contexts into larger theories that address both social and technical dynamics at individual, group, or organizational levels [69]. Such integration would be enabled by meta-theoretical understandings that describe and relate the elements of both the technical and social subsystems. Meta-theoretical discussions exist in IS reference disciplines such as library science [50], marketing [11], and management science [80]; however, these discussions have been limited in the IS literature. Arguments outlining the need for these types of integrative theories have recently emerged in prominent IS journals and conferences where researchers have called for a "good grand theory" or a meta-theory for IS [23, 41, 69, 106].

This paper has two goals. First, it identifies and presents the elements required in a meta-theory. Even though a number of papers discussing the constituents of a theory exist in IS literature [8, 127], the concept of meta-theorizing has not been adequately addressed. Without a clear understanding of what constitutes a meta-theory, a theory that links across theory domains, we argue that IS will continue to suffer from narrow studies whose findings cannot be related.

Second, the paper discusses how adaptive structuration theory (AST) can serve as a meta-theory for understanding IS within STS (organizational work systems) that offers a solution to a core IS research need. AST derives from structuration theory with the addition of specifically accounting for the presence and effects of technology artifacts. AST research has had a considerable effect on IS research, with more than 65 studies conducted since 1983 [60]. Recent reviews on structuration theory [60] and AST [95] have noted AST's importance for IS research and called for further application. At the same time, they give little indication as to how to derive the metatheoretical value AST has for understanding STS. Under our second goal, we present how AST can be used to accomplish the three main applications of a meta-theory: provide an overarching perspective, facilitate theory development, and provide a deeper understanding of a theory. We provide an IS example of each application as a guideline for future research.

\section{Meta-Studies in IS}

Many meta-studies of IS research appear in top IS journals, but little attention has been paid to the nature of "meta"-studies in IS research. In order to situate the present paper, we first define meta-theorization and its place within IS research.

A meta-study focuses on synthesizing knowledge in a particular area, summarizing the findings, and providing guidelines for future research in the area. Meta-studies can 


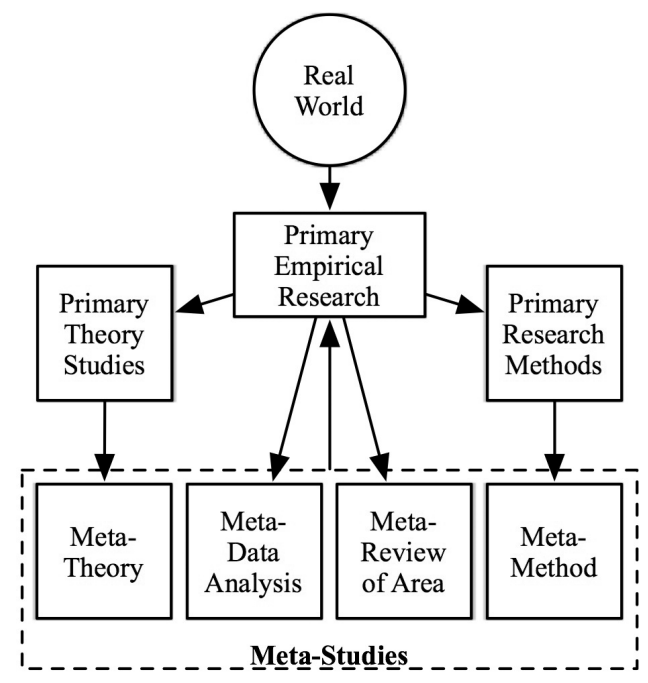

Figure 1. Meta-Study Relationship Source: Adapted from [131].

be classified into four broad categories - meta-data analyses, meta-method analyses, meta-reviews, and meta-theorizations (Figure 1).

Meta-data analyses aggregate raw data collected from various empirical studies to synthesize the findings related to the same phenomenon [38]. These studies focus on the antecedents and outcomes of a specific phenomenon under investigation, focusing on the importance of the various constructs as well as the effect size of the relationships. For example, Dennis et al. [24] performed a meta-data analysis of the data collected in group decision support systems (GDSS) studies.

Meta-method analyses examine research methods, often focusing on how a given method has been applied in multiple studies. These studies elucidate methodological presuppositions necessary for application of a given method, evaluate efficacy of methods, or codify rules of usage [36]. For example, Chin [17] presented a review of the issues involved in structural equation modeling and suggested guidelines for IS researchers.

A meta-review, distinct from meta-data analysis, provides an overview of a specific topic, area, or domain. Meta-reviews aim at producing a clear understanding of the current status for the domain and what remains to be done as of the time of the review. Numerous meta-reviews exist in the IS field. For example, Alavi and Leidner's [3] work summarizes the domain of knowledge management. Other examples address virtual teams [92, 97] and group support systems (GSS) literature [34, 83].

The last category of meta-studies is meta-theorization. Meta-theorization assembles what is known about the functioning of a given theory through examination of studies using the theory or set of theories [100]. The outcome of meta-theorization is an enhanced theory description or a meta-theory that allows the synthesis of multiple theories within a nomological framework for simultaneously understanding them [120]. 
A meta-theory outlines an ontological network of constructs and relationships applicable over several areas of investigation [79, 111]. Meta-theories are usually very general in nature and help shape disciplines. Perhaps the best known example in behavioral science is the work on meta-sociology, which presented a synthesis of the work done in the field of sociology [88]. An example of meta-theorization from the IS field was a study describing and producing a unified model for user acceptance of technology [121]. That study examined eight smaller theories focusing on user acceptance of technology. The analysis resulted in a synthesized unified view called the unified theory of acceptance and use of technology (UTAUT), a meta-theory. The study concluded with an evaluation of the usefulness of applying the resulting metatheory research lens.

A key difference between a meta-review and a meta-theorization relates to the focus of the study. The former focuses on summing up what is and is not known within a particular established domain with the goal of guiding future research, and the latter involves a meta-study of an existing theory or theories across domains in order to evaluate the research done using a particular theory or set of theories [36]. Like the other forms of meta-study, meta-theorizing draws heavily on empirical studies in the field (see Figure 1). Thus, such work is done after the theory has been developed and applied in a substantial number of primary studies and areas [90]. Meta-theories could also be useful as a guiding framework and organizing tool for a meta-data analyses, meta-reviews, or meta-method analyses.

Ritzer [100] identified three characteristics of a good meta-theory:

1. Ability to provide overarching perspectives. Meta-theories serve as a framework for developing overarching perspectives for a specific domain [120]. From a researcher perspective, a good meta-theory can be used to summarize literature and identify research gaps in an area. Such a theoretical perspective could be especially important for the field of IS as it currently struggles with its identity and understanding its core; a successful meta-theory would help clarify and solidify this core [74].

2. Ability to facilitate theory development. Meta-theories provide a lens through which one or more types of context can be understood. They provide an ontological arrangement of constructs in a system and a set of meta-theoretical assumptions or propositions. These constructs and propositions can be used as guidelines for creating context- or system-specific theoretical models. This process is similar to common empirical theory development in that it seeks to build theory; but distinct in that meta-theorizing draws on theorizing as its sample rather than direct empiricism.

3. Ability to provide a deeper understanding of a theory. A meta-theory can be used to create a better, more profound understanding of a given small " $t$ " theory [41]. It makes a theory a subject matter of study and discusses the theory through the principles that are encompassed in the meta-theory [105]. For example, the meta-theory of user acceptance of technology referenced above could be used to get a deeper understanding of any technology acceptance theory. 


\section{AST as a Meta-Theory for IS}

Organizational and IS research has been influenced by four dominant meta-theoretical perspectives, each with its own assumptions. Each of these perspectives provides a "net cast to catch what we call 'the world': to rationalize, to explain, and to master it" [96, p. 37], qualifying them as theory. We start by reviewing the various meta-theoretical perspectives followed by a discussion of AST. We also identify how AST can serve as a useful meta-theory for understanding IS within STS. To be clear, when we refer to the domain of IS within STS, we identify the domain of IS technology being used in organizational work systems over time.

\section{Meta-Theoretical Perspectives}

A REVIEW OF IS LITERATURE OUTLINES two dominant philosophical camps used to explore IS - the structuralist and the voluntarist (see Table 1). The structuralist approach, also referred to as the deterministic, contingency, or variance approach, holds that given a change in the initial set of structures (social, technical, or environmental conditions), the results are predictable $[61,73]$. This has been the dominant approach in the IS area. It emphasizes the fundamental importance of physical artifacts in explaining a phenomenon of interest. This approach assumes that factors outside the control of the individuals in a system heavily determine the system outcomes. The actor's choices are assumed to be illusionary, marginal, or trivial [90]. The use of this perspective is unfortunate for any IS research involving human interactions with technology, because humans have independent motives and intentions, and IS phenomena exist within social contexts in which actors have agency to manipulate constructs during change processes [67].

Research in IS using the second perspective-that is, voluntarist or process approach-is limited. This approach assumes that humans make real choices and influence conditions and outcomes. It argues for a focus on the role of individuals interacting with IS, also termed actors, agents, or learners. Recent exemplary IS research calling for this approach has focused on developing a user-centric agenda [105] and has argued for conceptualizing IS users as social actors [67]. A limitation of a voluntarist approach for understanding IS phenomena is its deemphasis of structure or the role of the technology artifact [86].

An important theoretical perspective that has attempted to integrate structural and voluntarist views is structuration theory (see Table 1) [37]. Although structuration theory finds its home in sociology literature, it has had a profound effect on IS [85, 95, 101] and management research [98]. The theory outlines three kinds of structuressignification, domination, and legitimation. The core argument of this theory is that structures exist only in the minds of human actors or as traces of human actions. Structuration is defined as the conditions governing the continuity or transmutation of structures, and therefore, the reproduction of social systems. The focus is on the intersubjectivity of actors enacting structures - that is, how they understand and come to use these structures. Structurationist analyses in IS have helped to increase our un- 
Table 1. Meta-Theoretical Perspectives in IS

\begin{tabular}{|c|c|c|c|c|}
\hline & $\begin{array}{c}\text { Structuralist } \\
\text { approach [90] }\end{array}$ & $\begin{array}{l}\text { Voluntarist } \\
\text { approach }\end{array}$ & $\begin{array}{l}\text { Structuration } \\
\text { theory [37] }\end{array}$ & $\begin{array}{c}\text { Adaptive } \\
\text { structuration } \\
\text { theory [27] }\end{array}$ \\
\hline Artifact & $\begin{array}{l}\text { Norms and } \\
\text { cultures that } \\
\text { limit, shape, } \\
\text { or heavily } \\
\text { constrain }\end{array}$ & $\begin{array}{l}\text { Amendable } \\
\text { products of } \\
\text { free agents: } \\
\text { constrain but } \\
\text { also enable }\end{array}$ & $\begin{array}{l}\text { Cognitive } \\
\text { constraint/ } \\
\text { resource: } \\
\text { "exist only } \\
\text { as memory } \\
\text { traces," }\end{array}$ & $\begin{array}{l}\text { Cognitive } \\
\text { and objective } \\
\text { constraint/ } \\
\text { resource with } \\
\text { intention } \\
\text { (spirit) }\end{array}$ \\
\hline $\begin{array}{l}\text { Actors/ } \\
\text { agents }\end{array}$ & $\begin{array}{l}\text { Choices: } \\
\text { illusory, } \\
\text { marginal, } \\
\text { or trivial. } \\
\text { Norms/ } \\
\text { culture } \\
\text { dictate } \\
\text { outcomes }\end{array}$ & $\begin{array}{l}\text { Choices: } \\
\text { real }\end{array}$ & $\begin{array}{l}\text { Choices: } \\
\text { real, } \\
\text { perceptual }\end{array}$ & $\begin{array}{l}\text { Choices: } \\
\text { real, } \\
\text { perceptual. } \\
\text { Limited to } \\
\text { real options } \\
\text { in objective } \\
\text { structures }\end{array}$ \\
\hline
\end{tabular}

derstanding of important IS-based contemporary phenomena in a multitude of areas. Recent articles have summarized structuration's contributions [59, 60, 101].

The earliest review of the use of structuration theory in IS research was the Walsham and Han [124] review. They argue that structuration theory would be a useful metatheory for IS research efforts. In the authors' words, the theory "provides a highlevel conceptual scheme to order and inform processes of enquiry into social life; it can be thought of, at one level, as a meta-theory within which other theories and methodologies can be contained" [124, p. 77]. The authors provide examples of how structuration theory concepts can be applied to guide IS theory development. Two additional early reviews of literature concerning IS and structuration theory, Jones [59] and Rose [101], advance the themes of the Walsham and Han paper; however, the meta-theory perspective is not stressed or developed in these reviews. Since these papers, major efforts have extended structuration theory and addressed some of its limitations [27, 84].

More recently, Jones and Karsten [60] provide an extensive meta-review of the previous research and reviews through 2004 on the use of structuration theory in IS. They conclude in agreement with Poole and DeSanctis's [95] comment to those researching the relationships of IS within organizational systems: "[AST is . . . one of the most influential . . . theoretical paradigms influencing IS research in the last decade or more ... the theoretical lens of choice for most scholars" [60, p. 138]. Jones and Karsten also found that structuration research has predominantly derived from a structural perspective even though it is proposed as an approach for integrating structural and voluntarist perspectives. They argue that future research must pay equal attention to this interaction between social actors and structures. 
The use of structuration theory for understanding sociotechnical organizational systems has two critical limitations. First, structuration "conflates" structure and agency - that is, it reduces the understanding of structure to enacted cognitions [10, 101]. IS, unlike other fields such as organizational behavior, is concerned with the use of artifacts in human-machine systems. The artifacts have properties of physical objects (machines or technology) and enforce or limit human behavior. Conflating weakens the ability to understand technology's role in sociotechnical change. The theory deemphasizes or dismisses that structures are preconstituted (e.g., embedded in technology by designers during development) and influence action $[6,68]$.

The second limitation involves purposeful change. Structuration was designed to explain social systems within society; however, organizational systems are designed with specific goals in mind. Although structuration offers a mechanism for explaining the reproduction of social structures within these systems, it does not explain why certain structures succeed or become institutionalized [6].

The Jones and Karsten [60] review does not discuss the earlier theme of the usefulness of structuration theory as a meta-theory. A number of the review's conclusions would indicate a lack of usefulness. The following limitations were pointed out and suggested as key areas of research opportunity: lack of cumulative research tradition, lack of a consistent structurational account of technology, and limited use to develop and apply IS-specific versions of structuration theory. The cumulative research tradition and the development of IS-specific theories limitations would provide evidence that structuration theory does not meet our first two criteria for good meta-theory discussed above. In addition, we could not find any use of structuration theory to provide a deeper understanding of a specific IS theory (criterion 3 above for a good meta-theory). Thus, given these limitations, we concluded that structuration theory is not the best candidate for an IS meta-theory within an STS.

Adaptive structuration theory draws on some of the assumptions of structuration theory. Importantly, it adds the information technology (IT) artifact in IS structures as a part of the social context [27]. In this way, AST does a better job of integrating the voluntarist and the structural approaches within an augmented structuration theory. AST allows structures to be separate from the actions or minds of actors making structures, and thus, making structures an objective part of the actor's context, allowing them to play an active role in the processes, along with the actors [84].

AST argues that the influence of these IS objective structures is moderated by the actions of the actors and their moves [9, 26, 27, 85]. In essence, AST enables the role of IS to be isolated and examined in conjunction with actors' actions during change processes. Thus, AST makes both technology and human agents part of the system, accounting for the interplay between people and technology, as well as the full predictability of IS use in individuals, groups, and organizations [35]. This allows AST to preserve the predictive potential of a deterministic perspective, while accounting for interpretive flexibility of the process perspective [40].

This initial analysis suggests that AST has the potential to be a good IS meta-theory conforming to STS. To fulfill this role, researchers will need to understand the benefits of AST as a meta-theory and how to apply it. The rest of the paper addresses this 
need by first overviewing AST and then providing examples of how it meets the three criteria for a good meta-theory: providing an overarching perspective on a domain of interest, facilitating theory development, and providing deeper understanding of one or more theories within a domain.

\section{A Discussion on AST: Important Tenets}

As A META-THEORY, AST PROVIDES AN ONTOLOGICAL FRAMEWORK of constructs, assumptions, and arguments. Poole and DeSanctis [95] identify seven requirements for applying AST effectively that will evoke the necessary understanding for each STS component given in Figure 2: (1) identification of structures, (2) relationships among structures, (3) description of the system, (4) appropriation of the structures (moves), (5) contextual impact or influence of structures, (6) influence of actors, and (7) power dynamics. We begin by mapping these constructs to a sociotechnical view of a bounded work system (see Figure 2).

AST outlines two basic premises. The first premise, incorporating the first three requirements, relates to the influence of structures embedded in a context. Structures are rules, resources, and capabilities available in a work system [26]. Social and technical structures compose an STS. For these fundamental structures, STS provides two subsystems or sets of variables [14]. The process and technology components comprise the technical subsystem. People (users, programmers, end users, etc.) and organizations (groups, teams, departments etc.) comprise the social structures. The work system's process, technology, and organization variable sets establish initial and potential structures [85]. The people are the actors or agents in the system.

To identify the structural potential and effect in a particular STS involving IS, one needs to specify the technology structure and its relationships with other elements. AST describes technology structures in three ways-spirit, features, and dimensions (see Table 2) [26]. AST states that in a directed or purposeful STS involving IS, structures reflect the beliefs, values, and goals as understood by the designer(s) of the work system - that is, they are designed to reflect a spirit. The spirit is the "official line" that the technology structures present to the participants regarding how to act, interpret the features, and fill in the gaps in the procedures that are not explicitly specified [26].

Features are options and capabilities offered by (explicitly) or associated (implicitly) with a structure [26]. For example, case studies have been broadly classified as the McAleer Interactive Case Analysis (MICA) and Harvard Case Method (HCM) depending on the following features: role of the instructor, participant, and the case guidelines [29]. Although useful in understanding the two different case study methods, the study comparing MICA and HCM failed to attribute learning differences to the different features offered by each method [29]. Similarly, most technology-mediated learning research in the IS and education fields has also focused on the features in learning methods $[44,71]$. The implementation differences in features, along with the variety of learning method features, have led to inconsistent empirical comparisons, resulting in a lack of generalizable research results. We argue that the limitations of 


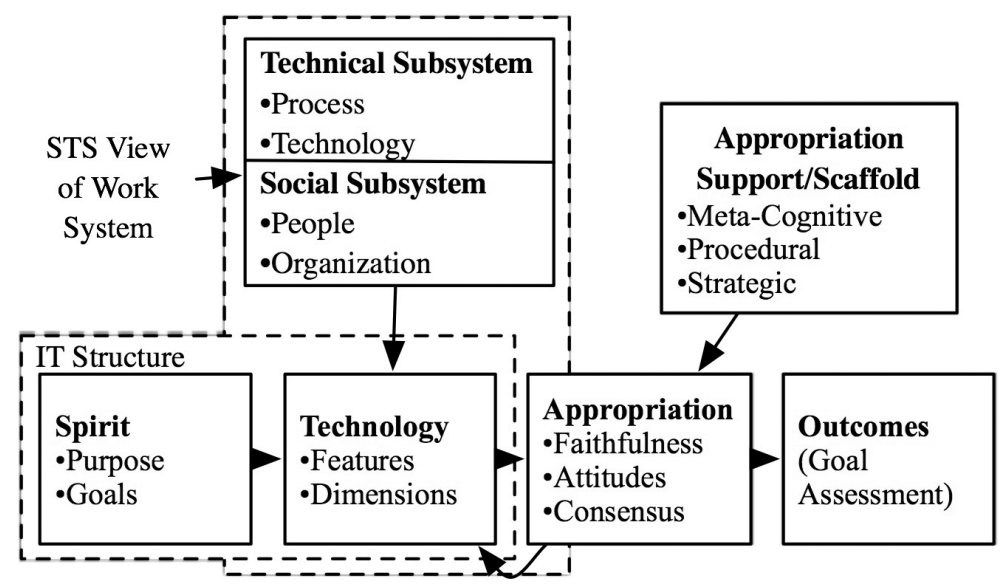

Figure 2. Adaptive Structuration Theory-A Map of IS Within an STS

Table 2. Structural Descriptors in AST

\begin{tabular}{ll}
$\begin{array}{l}\text { Structural } \\
\text { descriptor }\end{array}$ & Definition \\
\hline Spirit & $\begin{array}{l}\text { The general intent of the technology as it is presented to the user } \\
\text { It is reflected in the design and implementation. }\end{array}$ \\
Features & $\begin{array}{l}\text { Specific types of capabilities, rules, and resources offered by or } \\
\text { associated with the structures. }\end{array}$ \\
Dimensions & $\begin{array}{l}\text { An aspect or characteristic of a structure that reflects a bundled } \\
\text { set of features implemented in a particular context. }\end{array}$
\end{tabular}

this feature approach would apply to most IS comparison studies. Thus, spirit and features are not enough to explain structural influences on results.

The AST answer to this problem is to describe structures in terms of structural dimensions. A dimension describes an aspect of structure as a resource or constraint in work $[26,44]$. Dimensions are scalable, reflecting the amount of a given characteristic manifested in the structure. Sets of features are used to create a particular level of a dimension. For example, Silver used the dimension of restrictiveness to differentiate between decision support systems [110]. Restrictiveness measures the degree to which the features of a system limit the decision-making process. Features such as ability to show a spreadsheet, implement functions, and executive programming code were used to measure restrictiveness of a decision support system. Technology features can positively or negatively influence existing dimensions of the work system, or technology can provide dimensions that would not otherwise exist.

This focus on dimensions is unique to AST and helps IS researchers not only in enhancing our understanding of the work system but also in developing hypotheses and explaining research results in STS. In the above example, Desiraju and Gopinath 
Table 3. IT Structures: A Sample of Features and Dimensions

\begin{tabular}{|c|c|c|c|}
\hline $\begin{array}{l}\text { Structural } \\
\text { dimension set }\end{array}$ & $\begin{array}{l}\text { Communication } \\
\text { support }\end{array}$ & $\begin{array}{c}\text { Process } \\
\text { structuring }\end{array}$ & $\begin{array}{c}\text { Information } \\
\text { processing }\end{array}$ \\
\hline Dimensions* & $\begin{array}{l}\text { Synchronicity } \\
\text { Anonymity } \\
\text { Simultaneity } \\
\text { Interactivity } \\
\text { Telepresence } \\
\text { Richness }\end{array}$ & $\begin{array}{l}\text { Restrictiveness } \\
\text { Self-directivity/ } \\
\quad \text { learner control } \\
\text { Flexibility } \\
\text { Synchronicity }\end{array}$ & $\begin{array}{l}\text { Comprehensiveness } \\
\text { Sophistication } \\
\text { Feedback } \\
\text { Personalization } \\
\text { Authenticity }\end{array}$ \\
\hline $\begin{array}{l}\text { Features } \\
\text { examples }\end{array}$ & $\begin{array}{l}\text { Chat } \\
\text { E-mail } \\
\text { Audio/video/ } \\
\quad \text { text } \\
\text { Brainstorming }\end{array}$ & $\begin{array}{l}\text { Scheduling } \\
\text { Syllabus and } \\
\text { course } \\
\text { organizer } \\
\text { Learning } \\
\text { sequence }\end{array}$ & $\begin{array}{l}\text { Voting } \\
\text { Decision tools } \\
\text { Simulated } \\
\quad \text { environment }\end{array}$ \\
\hline
\end{tabular}

* The Appendix provides the source references for each dimension.

[29] were able to explain their study results by focusing on the dimensions of feedback and restrictiveness of the case-based learning methods. Scaling of dimensions can be accomplished by consulting manuals, reviewing the statements of designers, educators, or noting the comments of participants [26].

Based on a review of IS literature, we identified a useful set of IS structural dimensions. Table 3 provides a list of these, broadly classifying them by technology type: communication support, process structuring, and information processing [132]. For example, the GroupSystems ${ }^{\mathrm{TM}}$ brainstorming tool features the ability for participants to provide simultaneous input [83]. This input can be fully identified, partially blinded, or fully anonymous, varying the degree of the anonymity dimension [21]. The list in Table 3 represents major dimensions we found reviewing a large set of IS articles; however, research exploring and identifying a complete set of features and dimensions would be useful.

Together, the spirit, features, and dimensions of a structure form the structural potential, which participants can draw upon to generate particular patterns of interaction and change [85]. Once enacted, these patterns guide coordination among people and provide procedures for accomplishing their desired goal, such as intentional change (see Figure 2) [24]. Actors are purposeful in their actions and interact with the structures through the process of appropriation; that is, a process where actors learn and adapt the structures based on their interpretation of the spirit [95].

At the same time, AST does not discount the fact that new structures can be created during the appropriation process [60]. Actors in an STS can influence IS structures through "reciprocal causation." The structures are reproduced, refined, or discarded through interactions with actors. Thus, the process of appropriation itself may cause changes in structures - that is, a reciprocal causation process (represented by the feedback arrow between appropriation and structures in Figure 2). Poole and DeSanctis 
[94] identify nine categories of structuring moves actors can employ to exert this influence-direct appropriation, substitution, combination, enlargement, constraint, contrast, affirmation, negation, and ambiguity or neutrality.

When analyzing technology appropriation, Poole and DeSanctis [93] suggest three constructs that indicate level of appropriation-faithfulness, attitudes, and level of consensus. That is, IS will have its maximal effect on the whole if the design principles are kept intact (faithfulness), if members do not react negatively to it (attitudes), and if members agree substantially over how the IS is used (consensus) (see Figure 2). Some generalized measures for faithfulness and consensus exist [103].

Per AST, the use of structures can be either faithful or ironic. This construct is unique to AST and provides an important insight into IS implementation over and above attitudes and consensus, which arguably have been the target of much IS adoption research. A faithful appropriation occurs when participants' interaction with the structures is consistent with the spirit [94]. Faithfulness is not necessarily concerned with the precise duplication of the procedures provided; rather, it is concerned with whether the structures are used in a manner consistent with the overall spirit. A unique or innovative use of the structures by the participant may well be a faithful appropriation as long as the use is consistent with the spirit that the technology is intended to promote [18].

Ironic appropriation occurs when the participants' interactions violate the spirit of the structures [93]. This introduces internal contradictions within the structures governing interaction. Over time, these contradictions will cause tensions in interactions that might lead to lower effectiveness of the structures.

AST provides a framework and move categories but does not explain why certain moves are more likely versus others, or what influences efficacy of these moves. When analyzing these, researchers need to draw on narrower theories that focus on actors, their intentions, and individual expected outcomes on adoption or usage of IS in given domains. Theories from sociology, such as the theory of reasoned action or theory of planned behavior, as well as IS theories of technology acceptance and diffusion, might fit this need. For example, a recent study examining the difference between potential adopters and actual users showed that potential adopters base their attitude on a richer set of innovation characteristics than users [64]. Although the study did not explicitly examine the concept of reciprocal causation, it does imply that users change their interpretation of the structures embedded in the technology as they interact with it. Thus, as these theories are integrated into an AST meta-theory framework, they create a systemic theoretical framework for investigating a specific context, and, over time, we can develop richer understandings of reciprocal causation and the interactions between structures and actors across studies and topics.

A vital area, through which managerial influence is exerted, although underresearched in IS, relates to appropriation support or scaffolds. A scaffold, a term borrowed from the education literature, provides initial assistance to enhance faithful acceptance of structures. Scaffolding gradually fades as actors become more independent, confident, and competent. Literature on scaffolds has focused predominantly on the effect of scaffolds on goal assessment outcomes [48]. Within the AST framework, scaffolds 
influence appropriation of the work system structures, including IS structures (see Figure 2). The AST literature has not paid much attention to scaffolding though some empirical research indicates that appropriation support or a scaffold can be critical for successful appropriation in the areas of virtual teams [116] and GDSS usage [70].

Three types of process scaffolds have been identified in the literature-meta-cognitive, procedural, and strategic (Figure 2) [42, 48]. Meta-cognitive scaffolds support individual reflection on structures, such as soliciting estimates of current understanding or cuing participants to identify prior related experiences they can reference. Procedural scaffolding helps participants make navigation decisions, such as how to utilize available resources and tools. Empirical studies in GSS support the use of procedural scaffolds, especially those provided through facilitation [24]. Strategic scaffolds support participants in anticipating their interactions, such as analyzing, planning, and making tactical decisions. Hilmer and Dennis [49] used different decision-making techniques in GSS and found positive support for strategic scaffolding. This process perspective for supporting appropriation within AST through scaffolds provides researchers with the ability to conceptualize manipulation of usage and value gained from IS within an STS in order to explain its stability and adaptations as well as the impact it has on goal achievement (outcomes).

\section{Limits and Criticisms of an AST Approach}

RESEARCHERS RAISE TWO CENTRAL CRITICISMS about the application of AST. First, the preexistence of structures within a technology is a departure from structuration theory and has come under significant criticism [85]. While some researchers have argued that structures are constantly changing during the development phase of the application [128], others have argued that applications keep evolving even after they have been deployed [20]. In either case, researchers have argued that it is futile to study structures that exist in a technology. The problem with this criticism is the focus on structural features (which are either used or not) rather than the structural dimensions (which may represent a continuous scale). Recent research provides empirical evidence in this regard. It indicates that not only do structures in existing technology have an influence on future development [16], but embedded structures in deployed technology have been shown to have an influence on other outcomes such as organizational resilience [30,54]. Thus, we cannot expect precisely linear results from adding IT artifacts to work groups, but we can expect that the structures within an IT artifact will have some persistence in their effect across settings, particularly when we look at them from the standpoint of their dimensions.

Another major criticism of AST in the literature deals with the concept of quality of use or appropriation of embedded structures. Structuration researchers have argued that appropriation relates to the choice of human being to enact a structure, thus arguing for an exclusive focus on emergent structures rather than the quality of use of embedded structures [85, 112]. Recent research asserts that not only do existing structures matter, but also the extent to which humans appropriate the structures does have a significant influence on the outcomes [19, 32]. 
Both of these criticisms highlight a final and fundamental problem that all STS approaches share, which is the complexity they introduce by intentionally including voluntarist influences as well as socio and technical system components. The result is a system in which each element may impact others, and the nature of interaction may change over time. AST does not provide a direct linear model of causation. Rather, it provides a framework into which other theories can be fitted to make contextually appropriate predictions about system behavior. Thus, the applicability and usefulness of AST as a meta-theory extends to creation of propositions and hypotheses for predicting relationships between structures, usage, and outcomes in specific situations. The embedded theories help identify the criticality, scope, and direction of impact as well as answer questions such as why certain structures have more effect than others. The embedded theories provide a more detailed account of constructs and relationships for specialized domains of IS. The illustration provided in the "Facilitate Theory Development" section of the paper shows how social cognitive theory (SCT) can be embedded in the AST meta-theory.

To be more specific to the terminology of AST, structures, usage, and outcomes are linked through a process of "reciprocal causation." This core mechanism of mutual influence during interaction has received relatively little attention by the research community as a criticism of AST, but we believe it is one of the elements of the theory that has made it difficult to apply and, thereby, limited its usefulness. To be useful, researchers must parse the cycles of reciprocal causation and embed other theories that explain the specific reasons structure may influence actors or actors may influence structures. This kind of additional complexity and resulting work is probably not worth considering for studies in which one can assume away either socio or technical influences ceteris paribus.

\section{Meta-Theoretic Applications of AST}

IN THE NEXT THREE SUBSECTIONS, WE ILLUSTRATE the meta-theoretic applications of AST to address the three primary characteristics of a useful meta-theory: the ability to provide an overarching perspective, facilitate theory development, and provide a deeper understanding of a theory.

\section{Overarching Perspective}

Prior work has struggled to gain an overarching perspective on IS within STS. AST provides a theoretically grounded lens for structuring literature in a domain (as suggested by Webster and Watson [126]). As discussed earlier, AST outlines seven requirements for applying AST effectively: (1) identification of structures, (2) relationships among structures, (3) description of the system, (4) appropriation of the structures (moves), (5) contextual impact or influence of structures, (6) influence of actors, and (7) power dynamics [95]. In order to understand a particular area, existing literature can be mapped to these seven requirements. Research focusing on structures or a 
set of structures and their impact can be grouped under 1 or 2; research focusing on actor-structure interaction and appropriation/structuration process maps to numbers 4 and 6. Group 3 includes research viewing the entire system as dynamic process and analyzing this nature, whereas 7 focuses on social governance. Group 5 contains research focusing on contextual system effects.

Applying this mapping for understanding IS phenomena in an STS domain enables researchers to conclusively understand what is known, since it is a framework outlining the necessary and sufficient elements of an STS domain involving an IS artifact. AST's mapping also indicates what is relatively unknown, as a complete understanding of any STS domain would require a full understanding of all of the seven requirements. Knowing where there exists a paucity of key understandings in an STS domain enables researchers to evaluate where their future contributions would be most valuable. One example of such an application occurs in the virtual teams domain, where existing literature was mapped to the seven requirements in order to examine which sorts of studies have already been conducted and to identify key missing areas (see Table 4) [116].

The process of mapping the literature to the meta-theory provides the lens lacking in major reviews [126]. It helps identify critical knowledge gaps, and thus motivates researchers to conduct research in the missing pieces of literature. The review shows that important research has been done in understanding the structural effects on virtual teams. Researchers have focused the effects of the information and communication technologies (ICT) or GSS, the conditions under which they were used as well as the structure of the group. Only limited research exists focusing on how to cause and manage structural adaptation within a virtual team setting-moves (4), actors (6), and power (7) in Table 4.

One of the uses of overarching perspective is to design a study to address the gaps highlighted. The study designed to address the gap in the literature summarized in Table 4 focused on virtual team leader technology facilitation: the actor (virtual team leader) and moves (technology facilitation behavior) [115]. The study used an AST research framework to create questions for structured two-hour interviews. The application of AST as a meta-theory ensured that the questions addressed and captured all of the structural (technology, organizational, process, and people) and adaptation system (the seven elements in Table 4) dimensions of an STS involving technology. The overarching perspective usefully isolated a beneficial area for research as well as ensured the necessary and sufficient STS structures were covered within the study to build the overarching perspective of technology adaptation facilitation in virtual teams. In the absence of such a meta-framework, the study would likely suffer from having too narrowly defined its scope thereby missing key elements of an STS involving IS. It may also have failed to adequately sample across appropriate contexts due to the immense amount of data collection required to capture the STS context without AST's guidance.

Other examples of AST being used to build an overarching perspective include the area of GSS [24], technology-mediated learning [45], and knowledge management 
Table 4. AST Overarching Perspective Summary for Virtual Teams Domain

\begin{tabular}{llc}
\hline Topic & Applicable studies (selected examples) & Quantity \\
\hline 1. Structures & $\begin{array}{l}\text { Common ICTs [12, 76, 99] } \\
\text { ICT communication capability [22, 108, 113, 133] }\end{array}$ & $>25$ \\
2. Relationships & $\begin{array}{l}\text { IS-people [22, 43, 75, 122, 123] } \\
\text { IS-process [53, 76, 77, 78, 132] }\end{array}$ & $\sim 10$ \\
3. System & $\begin{array}{l}\text { Trust [57] } \\
\text { Group structure and socialization [1, 2] }\end{array}$ & $\sim 20$ \\
4. Moves & $\begin{array}{l}\text { Proactive or reactive [66, 119] } \\
\text { Triggering events [52, 72, 102] }\end{array}$ & $\sim 10$ \\
5. Contextual & ICT impact [31]; many GSS and CMC & $>25$ \\
6. Actors & $\quad$ studies fit [34, 83, 92, 97] & \\
7. Power & Leader effectiveness [65] & $<5$ \\
\hline
\end{tabular}

theories [117]. This type of literature review highlights key gaps and guides future empirical research. Researchers may then use AST to guide their theory development.

\section{Facilitate Theory Development}

AST provides a template and a set of guidelines for creating context- or system-specific theoretical models [27, 95]. While an extensive review of empirical research using AST has been presented [60], our focus has been on domains that have used AST for theoretical model building. We found that AST has been applied in at least five theory development domains within IS to facilitate development of theoretical models (see Table 5). These models were isolated by reviewing major IS journals as well as interactions with researchers at the recent DeSanctis Conference (2006).

DeSanctis and Poole [27] discuss the implementation of AST principles in a GDSS domain. Their model drew on theories of conflict handling and social judgments among other theories. A similar model for group decision making using geographic information systems (GIS) was proposed as AST2 [56]. This model grouped structures into social/institutional, group, and GIS. The AST2 model focused on understanding the domain of participatory decision situations. In an examination of communication media preferences, researchers found the need to study individual preferences as well as established organizational practices and media constraints [40, 129]. These studies used theories of motivation to explain their results within an AST framework.

A fourth study focused on the technology-mediated learning (TML) domain examining the effectiveness of learning methods used in e-learning. This model illustrates how e-learning technology teams (if used) and learning techniques can all be combined, while continuing to focus on the learner and his or her actions [44]. This e-learning AST-based model used social cognitive and development theories to 


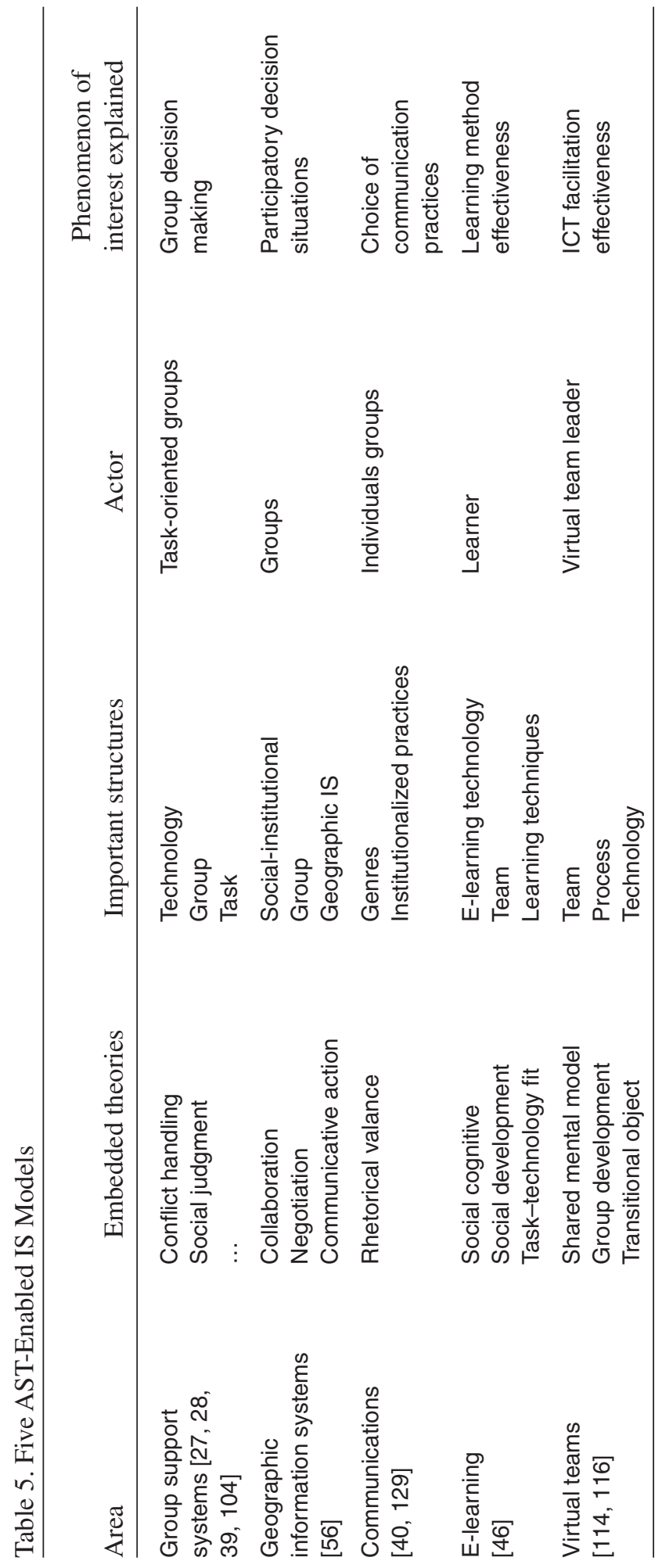




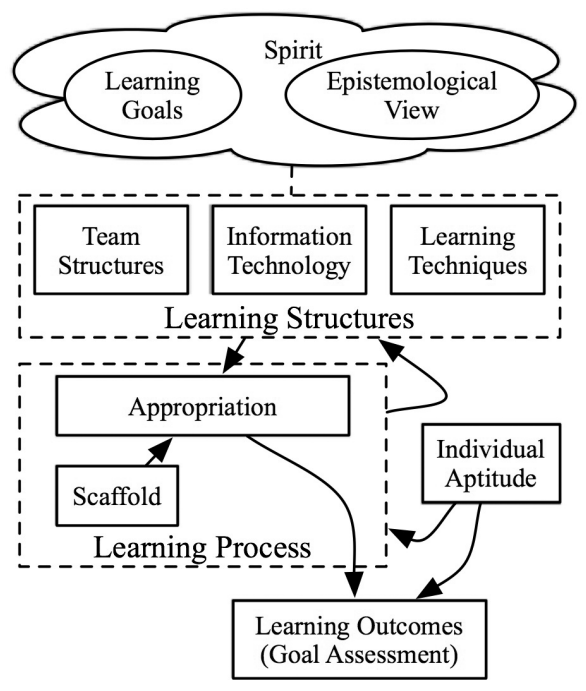

Figure 3. TML Model Enabled by AST

develop predictive hypotheses. The final domain is virtual teams; leader intervention moves and effects have been examined, applying shared mental model theory as well as group development and transitional object theory $[114,116]$. This virtual team research project was used in the previous section to illustrate how AST can be used to summarize the research literature.

To illustrate how AST enables theory building involving IS within an STS, we briefly present the e-learning example mentioned above and shown in Table 5: the development of a research model for TML in an end-user training context. To begin, we note that a theoretical model must exhibit falsifiability and utility to be acceptable as a theory [8].

The first step in the process of theory building is to map the ontological arrangement of constructs in the meta-theory to the phenomenon of interest. For AST, this means mapping the structures involved in the study domain. In TML, learning goals and epistemological perspective guide learning program design and represent the spirit though which the rest of the TML is designed (Figure 3). Learning goals focus on the desired knowledge to be attained [48, 62, 109], whereas epistemology establishes overarching beliefs and values about the nature of this knowledge and about what it means to "know" something [58]. The learning method, which stems from the "spirit" discussed earlier, embodies the external structural features and the dimensions. More specifically, three sets of structures characterize the TML domain: team or the social setup of the team, IT or the array of possible uses of technology, and learning techniques or the specific procedures to attain learning goals (see Figure 3) [45].

The concept of appropriation maps very well to the learning process. Appropriation deals with the learner (actor) interacting with structures to achieve the learning goals (Figure 3). The extent to which the learners faithfully use the learning method structures as well as their adaptations (moves) are all captured as a part of the learning process. 


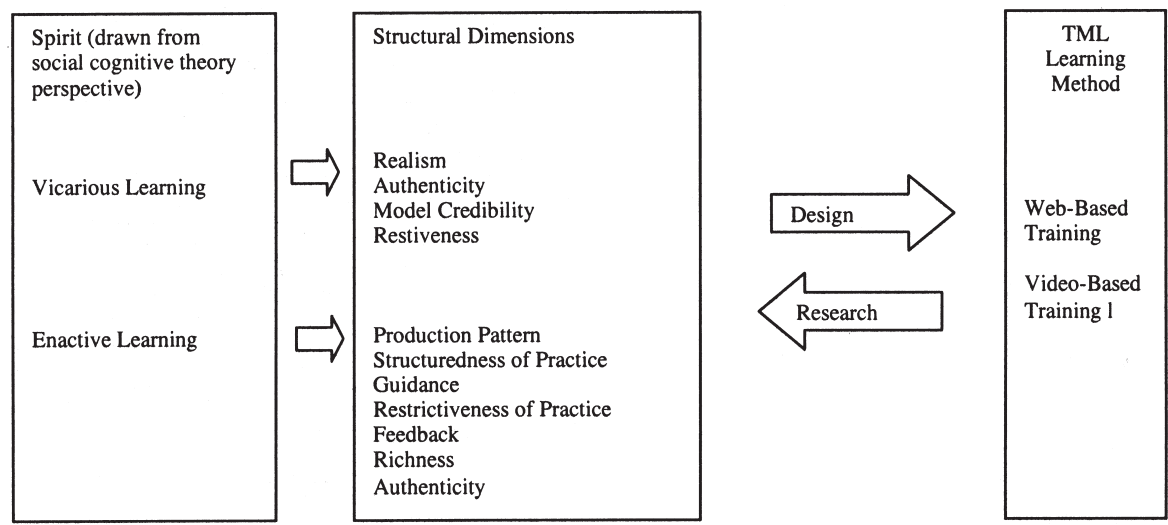

Figure 4. Relationship Between Theory, Structural Dimensions, and TML Tools

Most learning processes are scaffolded either by the instructor or by using technology tools that are conceptualized as appropriation support. For a detailed discussion of the theoretical model see Gupta and Bostrom [46].

Falsifiability, the second important condition that a theory needs to exhibit, determines if a theory is constructed such that empirical refutation is possible and relates to the ability to generate specific directional hypotheses/propositions within a specific phenomenon of interest. To achieve this, domain-specific theories may be applied to create hypotheses for the process of interest (in this case, learning) within the framework once structures are identified.

For instance, the most prevalent learning methods examined in end-user computer training are based on SCT. SCT focuses on two types of general learning methods that enhance learning: (1) observation of others' actions or behavior modeling and (2) observation of self-actions or enactive learning. Structural dimensions emerging out of these methods can be isolated [47]. The left side of Figure 4 shows the derivation of the dimensions from SCT. Behavioral modeling embodies the dimension of restrictiveness of demonstrations, richness of presentation, authenticity of presentation, and model prestige and competence. Similarly, enactive learning embodies dimensions of production pattern (lag between presentation and practice), structuredness, authenticity, feedback, and guidance.

Once these dimensions are identified, we can now argue that structural features of a learning method that present greater levels of these structural dimensions will have greater effectiveness. This provides for the creation of falsifiable hypotheses. Dimensions can be used to explain the impact of a specific learning method as well as compare different learning methods. The research arrow in Figure 4 illustrates this process. We take TML methods and evaluate them on the structural dimensions, comparing them in terms of which has more dimensional effect. This is discussed further in the next section.

Similarly, other variance and process theories can be used to generate hypotheses on the appropriation or process parts of the model. The AST framework enables 
Table 6. Mapping AST Constructs to a Research Context

\begin{tabular}{|c|c|}
\hline $\begin{array}{l}\text { AST constructs } \\
\text { translated to }\end{array}$ & Organizational learning system \\
\hline Spirit & $\begin{array}{l}\text { Learning goals } \\
\text { Epistemological perspective }\end{array}$ \\
\hline Structures & $\begin{array}{l}\text { Learning technology/IS } \\
\text { Learning techniques } \\
\text { Teams }\end{array}$ \\
\hline Dimensions & See Table 8 and Figure 4 \\
\hline Actors & Learners \\
\hline Context & Learning context/environment \\
\hline Appropriation & $\begin{array}{l}\text { How learners use the system; faithfulness of usage } \\
\text { patterns of learning technology, techniques, and teams } \\
\text { in the learning process }\end{array}$ \\
\hline $\begin{array}{l}\text { Reciprocal } \\
\text { causation }\end{array}$ & $\begin{array}{l}\text { Impact of learning technology, techniques, and teams on } \\
\text { learners' moves and actions in the learning process } \\
\text { Learners' actions to change the usage pattern of learning } \\
\text { technology, techniques, and teams in the learning process }\end{array}$ \\
\hline
\end{tabular}

these theories to be combined and tested in a coherent model. Whereas the overall model illustrated AST's utility, the use of specific theories makes the model falsifiable because expected outcomes and process results were specified and alternatives could be identified.

While AST provides a strong meta-framework for reasoning and theorizing, researchers often have a hard time with the language or terminology of its key constructs such as structures, spirit, appropriation, and so forth. Thus, it is important when using AST to develop a context- or system-specific theoretical model to translate the AST language into a more context-specific language. The example discussed in this section illustrated this translation of language in the TML model development process. A summary of the translation of language is shown in Table 6 .

\section{Ability to Provide a Deeper Understanding of a Theory}

As discussed previously, a good meta-theory can also be used to create a better, more profound understanding of a small " $t$ " theory. It discusses the theory through the constructs and assumptions that are encompassed in the meta-theory. In our review of the literature, we did not find an example of AST being applied in this way. However, we can expand on the example in the previous section to illustrate how this was done in a minor way.

The Gupta and Bostrom [46] research model and research outlined in the previous section use SCT to develop predictive hypotheses concerning differences in TML methods. Effective arguments for hypotheses comparing two TML methods based on 
SCT could not be developed directly from underlying theory, because SCT provides only a general discussion of vicarious and enactive learning. This discussion could not be directly mapped to explained differences in TML methods. Thus, the researchers used the AST constructs of structures and dimensions to provide more specificity to SCT. They identified the structural dimensions and then used these dimensions to outline the differences in TML methods as shown by the research arrow (shown in Figure 4). Some examples of their enactive learning dimensions are shown in Table 7, which outlines the differences between the two TML learning methods—video-based training and Web-based training (see [46] for details).

This AST dimensional analysis could be applied to other learning theories, as well as other IS theories and technologies. The dimensions derived for SCT shown in Figure 4 could now be applied in any other learning methods study. They provide a deeper understanding of what makes an effective SCT-based learning method. As shown by the design arrow in Figure 4, this perspective can also be used by a design researcher or systems designer to build a new TML tool. The researcher would start by dimensionalizing the core components of a validated learning theory and then implementing them in the TML tool.

\section{Conclusion and Summary}

THIS PAPER ACCOMPLISHED TWO GOALS. First, it identified and presented the elements of a good meta-theory. Second, and more importantly, it discussed how AST can serve as a meta-theory for understanding and researching IS within STS (sociotechnical work systems). AST provides an ideal nomological net to understand, investigate, and predict outcomes of an IS-induced change in an STS. We showed how AST meets the three criteria for a good meta-theory: provides overarching perspective of the field, the ability to facilitate theory development, and the ability to provide deeper understanding of a theory. AST use as a meta-theory has multiple benefits, outlined in Table 8 . These benefits were developed throughout the paper (Table 8 indicates sections where they were discussed) and are summarized in the discussion below.

We illustrated how AST provides an ability to enhance our understanding of a specific domain by providing an overarching perspective. Such a perspective is especially important for the IS field level. There is a constant struggle in IS to define the IS core, as well as set the boundaries of the field. Such boundaries need to incorporate all the elements of an STS driven by specific goals and it needs to be amiable to all levels of analysis (individual, group, and organizational). AST provides an ontological arrangement of constructs, their relationships, and propositions. In addition, and unlike the general structuration theory, AST is situated inside an organization and includes the IT artifact in its structures, incorporating the concept of outcomes and goals. Moreover, AST has already been used at all levels to create situation-specific models [95].

We also illustrated how AST can be used investigate a specific domain by facilitating theory development. As outlined earlier, AST provides the relationships between the constructs. However, it does not specify the nature of the relationship. 


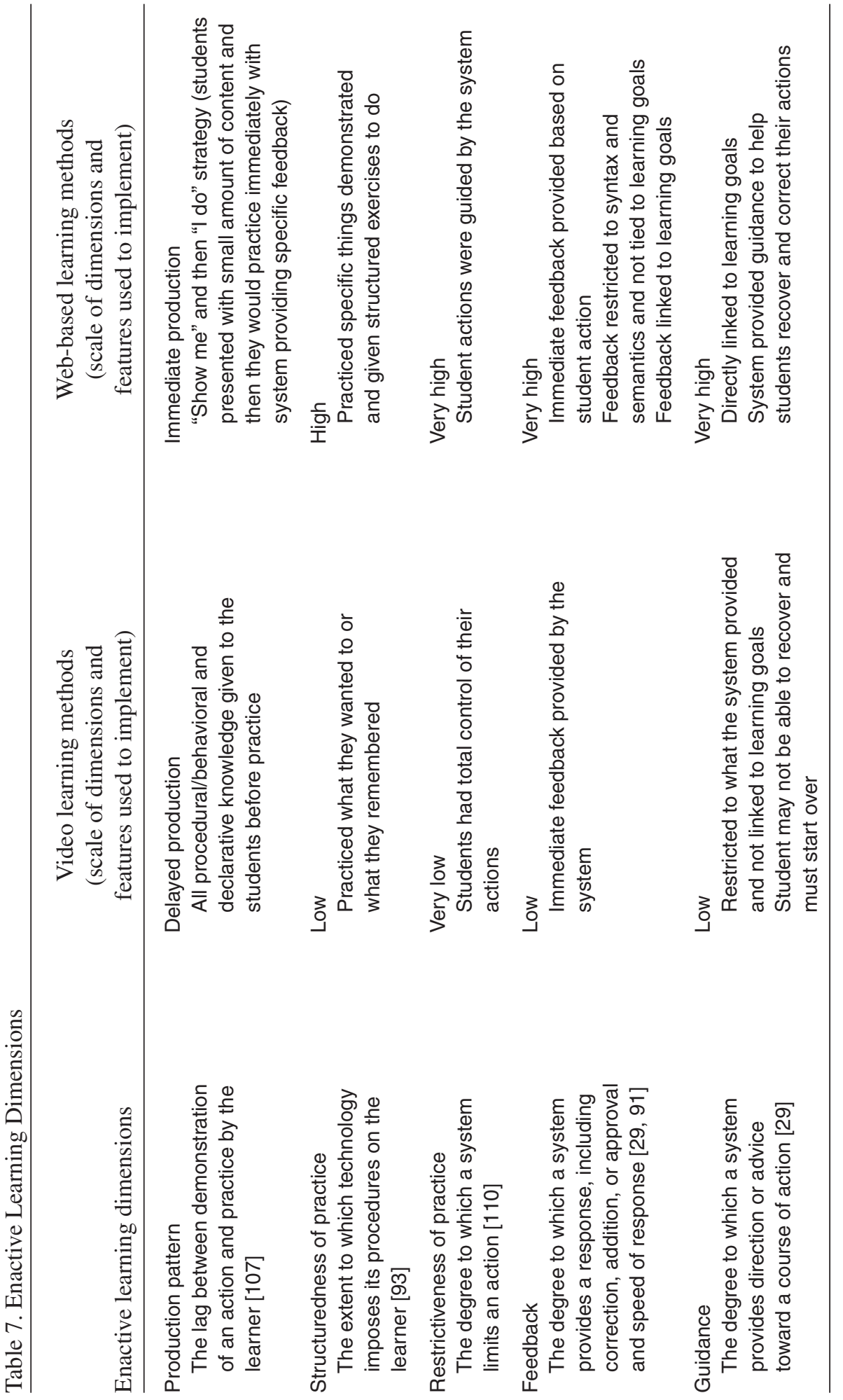




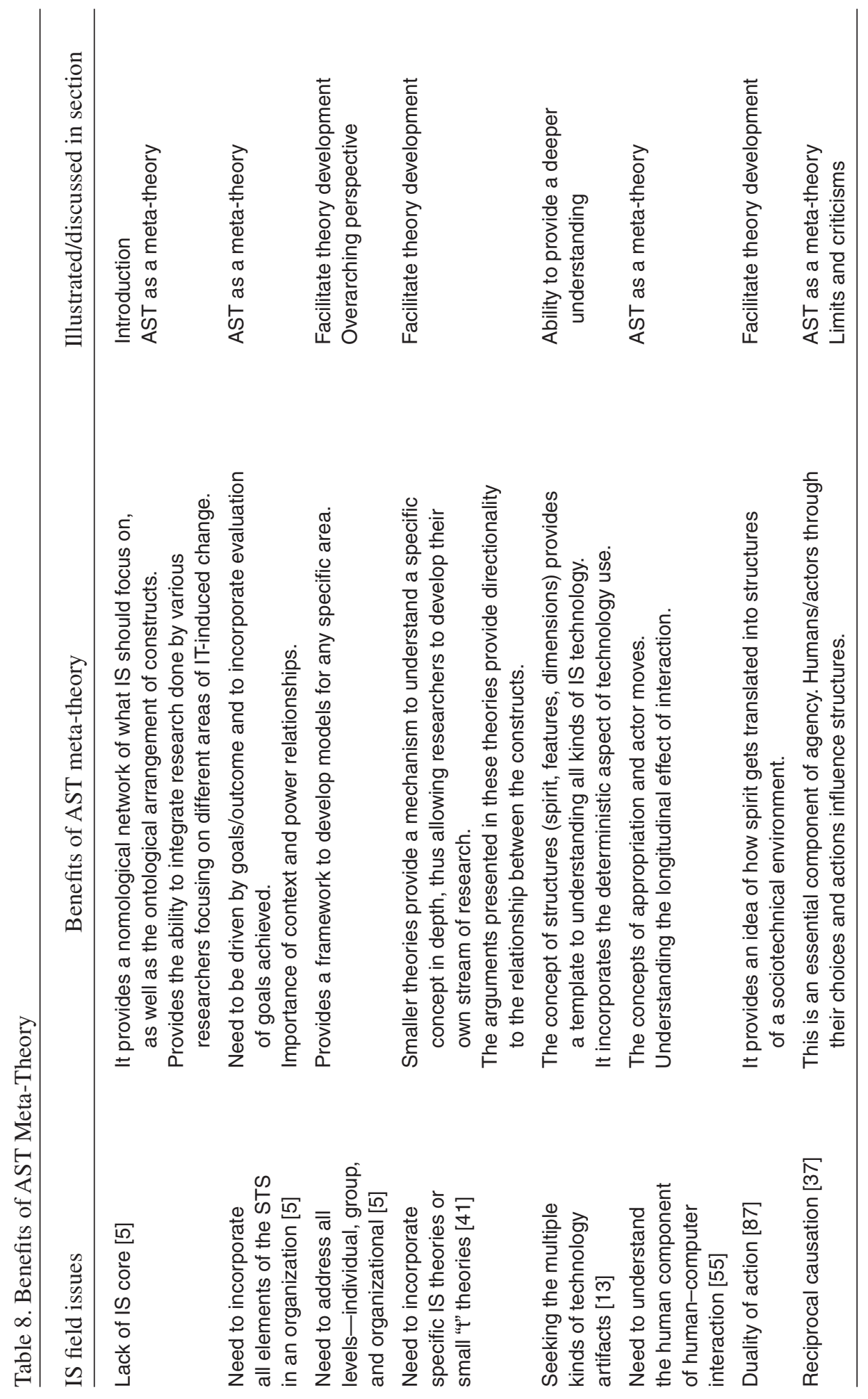


We believe that this is one of the strengths of AST as a meta-theory. The nature of the relationship is specific to the context. AST allows for context-specific theories to be embedded within its framework, enabling even otherwise incomparable theories within a shared domain to be combined to explicate the nature of relationship among key constructs [41]. This allows researchers to (1) build context-specific frameworks (the development of a technology-mediated learning model was outlined in the paper) which are falsifiable, (2) focus on their specific area of interest while keeping the larger nomological network in mind, and (3) provide a method to integrate various studies.

AST also contributes in enhancing our understanding of underlying theories (as illustrated earlier) as well as in differentiating between our core component- the technology artifact [13]. Technology artifacts in IS literature have primarily been classified according to the general type of system: record keeping, transaction processing, enterprise resource planning, decision support, group support, and so forth. While such classes help differentiate the chronology of systems evolution, the variation even within each of these categories, along with overlapping features among the categories, has made it difficult to build cumulative understandings of the IT artifact in general. As illustrated in the paper, AST has provided a method to describe these advanced IS that goes beyond the traditional classification. The concepts of structures (spirit, features, and dimensions) expanded in this paper provide AST with a mechanism to preserve the deterministic role of technology, which is a serious shortcoming of structuration theory. In addition, AST preserves the core component of appropriation (drawing from structuration theory) by focusing on human-computer interaction as a part of the process. Thus, it allows for choice of actions among human beings based on their interaction with the structures.

This leads us to some cautions or limitations that a researcher should consider in applying AST as a meta-theory. It is not a panacea to solve all ills. The AST metatheoretic approach we outlined offers researchers a means for taking an integrated sociotechnical view on organizational work systems. The trade-off is that this approach introduces reciprocal causation and the need to identify and operationalize structures within work systems. This complexity will unnecessarily complicate studies that might otherwise be able to hold social or technological influences constant, particularly those that are not interested in examining change due to technology usage over time. The additional complexity introduced by the AST meta-theoretic approach will require additional work on the part of researchers to identify appropriate theories to embed, or to summarize what is known according to the seven elements of AST, or to integrate what is known about any given theory.

Although the added complexity introduced by the AST meta-theoretic approach will require additional work, this paper has made a convincing argument that this approach is worth it. The benefits developed in the paper are summarized in Table 8. Using AST as a meta-theory provides the IS researcher with a means for attaining deeper meaning of an existing IS theory and for developing an overarching theoretical perspective for integrating research in an IS domain, as well as a guide for developing context-specific theories or models. 


\section{REFERENCES}

1. Ahuja, M.K., and Carley, K.M. Network structure in virtual organizations. Organization Science, 10, 6 (1999), 741-757.

2. Ahuja, M.K., and Galvin, J.E. Socialization in virtual groups. Journal of Management, 29, 2 (2003), 161-186.

3. Alavi, M., and Leidner, D. Review: Knowledge management and knowledge management systems: Conceptual foundations and research issues. MIS Quarterly, 25, 1 (2001), 107-136.

4. Alter, $S$. The work system method for understanding information systems and information system research. Communications of the AIS, 9, 6 (2002), 90-104.

5. Alter, S. 18 reasons why IT-reliant work systems should replace "the IT artifact" as the core subject matter of the IS field. Communications of the AIS, 12, 23 (2003), 366-395.

6. Archer, M. Social integration and system integration: Developing the distinction. Sociology, 30, 4 (1996), 679-700.

7. Avolio, B.J.; Kahai, S.S.; and Dodge, G.E. E-leadership: Implications for theory, research, and practice. Leadership Quarterly, 11, 4 (2000), 615-669.

8. Bacharach, S.B. Organizational theories: Some criteria for evaluation. Academy of Management Review, 14, 4 (1989), 496-515.

9. Barley, S.R. Technology as an occasion for structuring: Evidence from observations of CT scanners and the social order of radiology departments. Administrative Science Quarterly, 31, 1 (1986), 78-108.

10. Barley, S.R., and Tolbert, P.S. Institutionalization and structuration: Studying the links between action and institution. Organization Studies, 18, 1 (1997), 93-117.

11. Bartels, R. Marketing Theory and Metatheory. Chicago: Richard D. Irwin, 1970.

12. Becker, J.D., and Lee, A. Collaborative technology tools for virtual teaming. In W.D. Haserman and D.L. Nazareth (eds.), Proceedings of the Fifth Americas Conference on Information Systems. Atlanta: Association for Information Systems, 1999, pp. 334-336.

13. Benbasat, I., and Zmud, R.Z. The identity crisis within the IS discipline: Defining and communicating the discipline's core properties. MIS Quarterly, 27, 2 (2003), 183-194.

14. Bostrom, R.P., and Heinen, S.J. MIS problems and failures: A socio-technical perspectivePart 1: The causes. MIS Quarterly, 1, 3 (1977), 17-32.

15. Cats-Baril, W.L., and Huber, G.P. Decision support systems of ill-structured problems: An empirical study. Decision Sciences, 18, 3 (1987), 350-372.

16. Chae, B., and Poole, M.S. The surface of emergence in systems development: Agency, institutions, and large-scale information systems. European Journal of Information Systems, 14, 1 (2005), 19-36.

17. Chin, W.W. Issues and opinions on structural equation modeling. MIS Quarterly, 22, 1 (1998), vii-xvi.

18. Chin, W.W.; Gopal, A.; and Salisbury, W.D. Advancing the theory of adaptive structuration: The development of a scale to measure faithfulness of appropriation. Information Systems Research, 8, 4 (1997), 342-367.

19. Chu, T.-H., and Robey, D. Explaining changes in learning and work practice following the adoption of online learning: A human agency perspective. European Journal of Information Systems, 17, 1 (2008), 79-98.

20. Ciborra, C., and Lanzara, G.F. Designing networks in action: Formative contexts and post-modern systems development. In R. Clarke and J. Cameron (eds.), Managing Information Technology's Organizational Impact. Amsterdam: Elsevier Science, 1991, pp. 265-279.

21. Dennis, A.R., and Garfield, M.J. The adoption and use of GSS in project teams: Toward more participative processes and outcomes. MIS Quarterly, 27, 2 (2003), 289-323.

22. Dennis, A.R., and Valacich, J.S. Rethinking media richness: Towards a theory of media synchronicity. In R.H. Sprague Jr. (ed.), Proceedings of the Thirty-Second Annual Hawaii International Conference on System Sciences. Los Alamitos, CA: IEEE Computer Society Press, 1999 (available at www2.computer.org/plugins/dl/pdf/proceedings/hicss/1999/0001/01/00011017 .pdf?template $=1 \& \operatorname{loginState}=1 \&$ userData=anonymous-IP\%253A\%253A127.0.0.1).

23. Dennis, A.R., and Valacich, J. Conducting experimental research in information systems. Communications of the AIS, 7, 5 (2001) (available at http://aisel.aisnet.org/cais/vol7/ iss $1 / 5 /)$. 
24. Dennis, A.R.; Haley, B.J.; and Vandenberg, R.J. Understanding fit and appropriation effects in group support systems via meta-analysis. MIS Quarterly, 25, 2 (2001), 167-193.

25. DeSanctis, G., and Gallupe, R.B. A foundation for the study of group decision support systems. Management Science, 33, 5 (1987), 589-609.

26. DeSanctis, G., and Jackson, B.M. Coordination of information technology management: Team-based structures and computer-based communication systems. Journal of Management Information Systems, 10, 4 (Spring 1994), 85-110.

27. DeSanctis, G., and Poole, M.S. Capturing the complexity in advanced technology useAdaptive structuration theory. Organization Science, 5, 2 (1994), 121-147.

28. DeSanctis, G.; D’Onofrio, M.J.; Sambamurthy, V.; and Poole, M.S. Comprehensiveness and restrictiveness in group decision heuristics: Effects of computer support on consensus decision making. In J.I. DeGross, J.C. Henderson, and B.R. Konsynski (eds.), Proceedings of the Tenth International Conference on Information Systems. Atlanta: AIS, 1989, pp. 131-140.

29. Desiraju, R., and Gopinath, C. Encouraging participation in case discussions: A comparison of the MICA and the Harvard case methods. Journal of Management Education, 25, 4 (2001), 394-408.

30. Doherty, N.F.; Coombs, C.R.; and Loan-Clarke, J. A re-conceptualization of the interpretive flexibility of information technologies: Redressing the balance between the social and the technical. European Journal of Information Systems, 15, 6 (2006), 569-582.

31. Easley, R.F.; Devaraj, S.; and Crant, J.M. Relating collaborative technology use to teamwork quality and performance: An empirical analysis. Journal of Management Information Systems, 19, 4 (Spring 2003), 247-268.

32. Eason, K. Local sociotechnical system development in the NHS National Programme for Information Technology. Journal of Information Technology, 22, 3 (2007), 257-264.

33. Edmondson, A.C.; Bohmer, R.M.; and Pisano, G.P. Disrupted routines: Team learning and new technology implementation in hospitals. Administrative Science Quarterly, 46, 4 (2000), 685-716.

34. Fjermestad, J., and Hiltz, S.R. An assessment of group support systems experimental research: Methodology and results. Journal of Management Information Systems, 15, 3 (Winter 1998-99), 7-149.

35. Fulk, J. Social construction of communication technology. Academy of Management Journal, 36, 5 (1993), 921-950.

36. Furfey, P.H. The Scope and Method of Sociology: A Metasociological Treatise. New York: Harper, 1953.

37. Giddens, A. The Constitution of Society: Outline of the Theory of Structuration. Berkeley: University of California Press, 1984.

38. Glass, G.V. Primary, secondary, and meta-analysis of research. Educational Researcher, 5, 10 (1976), 3-8.

39. Gopal, A.; Bostrom, R.P.; and Chin, W.W. Applying adaptive structuring theory to investigate the process of group support systems use. Journal of Management Information Systems, 9, 3 (Winter 1992-93), 45-69.

40. Gouran, D.S. Exploiting the predictive potential of structuration theory. Communication Yearbook, 13 (1989), 313-322.

41. Gregor, S. The nature of theory in information systems. MIS Quarterly, 30, 3 (2006), 85-93.

42. Grise, M.L., and Gallupe, R.B. Information overload: Addressing the productivity paradox in face-to-face electronic meetings. Journal of Management Information Systems, 16, 3 (Winter 1999-2000), 157-185.

43. Grudin, J. Why CSCW applications fail: Problems in the design and evaluation of organizational interfaces. Communications of the ACM, 33 (1988), 85-93.

44. Gupta, S. New Approaches to End-User Training. Saarbrücken, Germany: VDM Verlag Dr. Mueller e.K., 2008.

45. Gupta, S., and Bostrom, R.P. End-user training: What we know, what we need to know? In K. Kaiser and T. Ryan (eds.), Proceedings of the ACM SIGMIS. New York: ACM Press, 2006, pp. 172-182.

46. Gupta, S., and Bostrom, R.P., E-learning: An integrative research model. Working Paper, University of Georgia, Athens, 2007. 
47. Gupta, S., and Bostrom, R.P. Longitudinal investigation of collaborative technologymediated learning in an end-user training context. Journal of the AIS (forthcoming).

48. Hannafin, M.J.; Kim, M.C.; and Kim, H. Reconciling research, theory, and practice in Web-based teaching and learning: The case for grounded design. Journal of Computing in Higher Education, 15, 2 (2004), 3-20.

49. Hilmer, K.M., and Dennis, A.R. Stimulating thinking: Cultivating better decisions with groupware through categorization. Journal of Management Information Systems, 17, 3 (Winter 2000-1), 93-114.

50. Hjørland, B. Theory and meta-theory of information science: A new interpretation. Journal of Documentation, 54, 5 (1998), 606-621.

51. Holland, C.P. The IS core - X: Information systems research and practice: IT artifact or a multidisciplinary subject? Communications of the AIS, 12, 40 (2003), 599-606.

52. Hollingstead, A.B.; McGrath, J.E.; and O'Connor, K.M. Group task performance and communication technology: A longitudinal study of computer-mediated versus face-to-face work groups. Small Group Research, 24, 3 (1993), 307-333.

53. Huang, W.W.; Kwok-Kee, W.; Watson, R.T.; and Tan, B.C.Y. Supporting virtual teambuilding with a GSS: An empirical investigation. Decision Support Systems, 34, 4 (2002), 359-367.

54. Ignatiadis, I., and Nandhakumar, J. The impact of enterprise systems on organizational resilience. Journal of Information Technology, 22, 1 (2007), 259-274.

55. Jacko, J.A., and Sears, A. The Human-Computer Interaction Handbook: Fundamentals, Evolving Technologies, and Emerging Applications. Mahwah, NJ: Lawrence Erlbaum, 2003.

56. Jankowski, P., and Nyerges, T. Geographic Information Systems for Group Decision Making: Towards a Participatory, Geographic Information Science. New York: Taylor \& Francis, 2001.

57. Jarvenpaa, S.L., and Leidner, D.E. Communication and trust in global virtual teams. Organization Science, 10, 6 (1999), 791-815.

58. Johnson, D.W., and Johnson, R.T. Making cooperative learning work. Theory Into Practice, 38, 2 (1999), 67-74.

59. Jones, M.R. Structuration theory. In W. Currie and R. Galliers (eds.), Rethinking Management Information Systems: An Interdisciplinary Perspective. Oxford: Oxford University Press, 1999, pp. 103-135.

60. Jones, M.R., and Karsten, H. Giddens structuration theory and information systems research. MIS Quarterly, 32, 1 (2008), 127-157.

61. Kamrava, M. Revolution revisited: The structuralist-voluntarist debate. Canadian Journal of Political Science, 32, 2 (1999), 317-345.

62. Kang, D., and Santhanam, R. A longitudinal field study of training practices in a collaborative application development. Journal of Management Information Systems, 20, 3 (Winter 2002-3), 257-281.

63. Kappelman, L.A.; McKeeman, R.; and Zhang, L. Early warning signs of IT project failure: The dominant dozen. Information Systems Management, 23, 4 (2006), 31-36.

64. Karahanna, E.; Straub, D.W.; and Chervany, N.L. Information technology adoption across time: A cross-sectional comparison of pre-adoption and post-adoption beliefs. MIS Quarterly, 23, 2 (June 1999), 183-213.

65. Kayworth, T.R., and Leidner, D.E. Leadership effectiveness in global virtual teams. Journal of Management Information Systems, 18, 3 (Winter 2001-2), 7-40.

66. Kelly, G.G., and Bostrom, R.P. A facilitator's general model for managing socioemotional issues in group support systems meeting environments. Journal of Management Information Systems, 14, 3 (Winter 1997-98), 23-45.

67. Lamb, R., and Kling, R. Reconceptualizing users as social actors in information systems research. MIS Quarterly, 27, 2 (2003), 197-235.

68. Layder, D. Key issues in structuration theory: Some critical remarks. Current Perspectives in Social Theory, 8 (1987), 2-46.

69. Lee, A. Research in information systems: What we haven't learned. MIS Quarterly, 25, 4 (2001), v-Xv.

70. Limayem, M.; Banerjee, P.; and Ma, L. Impact of GDSS: Opening the black box. Decision Support Systems, 42, 2 (2006), 945-957. 
71. Lou, Y.; Abrami, P.C.; and d'Apollonia, S. Small group and individual learning with technology: A meta-analysis. Review of Educational Research, 71, 3 (2001), 449-521.

72. Majchrzak, A.; Rice, R.E.; Malhotra, A.; King, N.; and Ba, S. Technology adaptation: The case of a computer-supported inter-organizational virtual team. MIS Quarterly, 24, 4 (2000), 569-600.

73. Markus, M.L., and Robey, D. Information technology and organizational change: Causal structure in theory and research. Management Science, 34, 5 (1988), 583-598.

74. Markus, M.L., and Saunders, C. Looking for a few good concepts ... and theories ... for the information systems field. MIS Quarterly, 31, 1 (2007), iii-vi.

75. Martins, L.L.; Gilson, L.L.; and Maynard, M.T. Virtual teams: What do we know and where do we go from here? Journal of Management, 30, 6 (2004), 805-835.

76. Maruping, L.M., and Agarwal, R. Managing team interpersonal processes through technology: A task-technology fit perspective. Journal of Applied Psychology, 89, 6 (2004), 975-990.

77. Mennecke, B.E., and Bradley, J. Making project groups work: The impact of structuring group roles on the performance and perception of information systems project teams. Journal of Computer Information Systems, 39, 1 (1998), 30-36.

78. Mennecke, B.E.; Valacich, J.S.; and Wheeler, B.C. The effects of media and task on user performance: A test of the task-media fit hypothesis. Group Decision and Negotiation, 9, 6 (2000), 507-529.

79. Milton, S.K., and Kazmiercak, E. Ontology as meta-theory: A perspective. Scandanavian Journal of Information Systems, 18, 1 (2006), 85-94.

80. Mitroff, I.I., and Betz, F. Dialectical decision theory: A meta-theory of decision-making. Management Science, 19, 1 (1972), 11-24.

81. Mumford, E. Redesigning Human Systems. Hershey, PA: Information Science, 2003.

82. Nicholson, B., and Sahay, S. Some political and cultural issues in the globalisation of software development: Case experience from Britain and India. Information \& Organization, 11, 1 (2001), 25-43.

83. Nunamaker, J.F., Jr.; Briggs, R.O.; Mittleman, D.D.; Vogel, D.R.; and Balthazard, P.A. Lessons from a dozen years of group support systems research: A discussion of lab and field findings. Journal of Management Information Systems, 13, 3 (Winter 1996-97), 163-207.

84. Orlikowski, W.J. The duality of technology: Rethinking the concept of technology in organizations. Organization Science, 3, 3 (1992), 398-427.

85. Orlikowski, W.J. Using technology and constituting structures: A practice lens for studying technology in organizations. Organization Science, 11, 4 (2000), 404-428.

86. Orlikowski, W.J., and Iacono, S. Desperately seeking the "IT" in IT research-A call to theorizing the IT artifact. Information Systems Research, 12, 2 (2001), 121-134.

87. Orlikowski, W.J., and Robey, D. Information technology and the structuring of organizations. Information Systems Research, 2, 2 (1991), 143-169.

88. Østerberg, D. Metasociology: An Inquiry into the Origins and Validity of Social Thought. Oslo: Norwegian University Press, 1988.

89. Papa, F.; Perugini, M.; and Spedaletti, S. Psychological factors in virtual classroom situations: A pilot study for a model of learning through technological devices. Behaviour \& Information Technology, 17, 4 (1998), 187-194.

90. Piaget, J. Structuralism. New York: Basic Books, 1970.

91. Piccoli, G.; Ahmad, R.; and Ives, B. Web-based virtual learning environments: A research framework and a preliminary assessment of effectiveness of basic IT skills training. MIS Quarterly, 25, 4 (2001), 401-426.

92. Pinsonneault, A., and Caya, O. Virtual teams: What we know, what we don't know. International Journal of e-Collaboration, 1, 3 (2005), 1-16.

93. Poole, M.S., and DeSanctis, G. Understanding the use of group decision support systems: The theory of adaptive structuration. In C. Steinfield and J. Fulk (eds.), Organizations and Communication Technology. Beverly Hills, CA: Sage, 1990, pp. 175-195.

94. Poole, M.S., and DeSanctis, G. Microlevel structuration in computer-supported group decision making. Human Communication Research, 19, 1 (1992), 5-49.

95. Poole, M.S., and DeSanctis, G. Structuration theory in information systems research: Methods and controversies. In M.E. Whitman and A. Woszczynski (eds.), Handbook of Information Systems Research. Hershey, PA: Idea Group, 2004, pp. 206-249. 
96. Popper, K.R. The Logic of Scientific Discovery, 3d ed. London: Hutchinson, 1968.

97. Powell, A.; Piccoli, G.; and Ives, B. Virtual teams: A review of current literature and directions for future research. DATABASE, 35, 1 (2004), 6-36.

98. Pozzebon, M. The influence of a structurationist view on strategic management research. Journal of Management Studies, 41, 2 (2004), 247-272.

99. Qureshi, S., and Vogel, D. Adaptiveness in virtual teams: Organisational challenges and research directions. Group Decision and Negotiation, 10, 1 (2001), 27-46.

100. Ritzer, G. Explorations in Social Theory: From Metatheorizing to Rationalization. Thousand Oaks, CA: Sage, 2001.

101. Rose, J., Evaluating the contribution of structuration theory to the information systems development. Paper presented at the Sixth European Conference on Information Systems, Aix-en-Provence, France, June 4-6, 1998,

102. Rutkowski, A.F.; Vogel, D.R.; van Genuchten, M.; Bemelmans, T.M.A.; and Favier, M. E-collaboration: The reality of virtuality. IEEE Transactions on Professional Communication, 45, 4 (2002), 219-230.

103. Salisbury, W.D.; Chin, W.W.; Gopal, A.; and Newsted, P.R. Research report: Better theory through measurement-Developing a scale to capture consensus on appropriation. Information Systems Research, 13, 1 (2002), 91-103.

104. Sambamurthy, V., and Poole, M.S. The effects of variations in capabilities of GDSS designs on management of cognitive conflict in groups. Information Systems Research, 3, 3 (1992), 224-251.

105. Sasidharan, S., and Santhanam, R. Technology-based training: Toward a learner-centric research agenda. In P. Zhang and D.F. Galletta (eds.), Human-Computer Interaction and Management Information Systems: Applications, Advances in Management Information Systems, vol. 6. Armonk, NY: M.E. Sharpe, 2006, pp. 247-257.

106. Schneberger, S.L.; Watson, H.J.; and Pollard, C.E. The efficacy of 'little t' theories. In R.H. Sprague Jr. (ed.), Proceedings of the Fortieth Annual Hawaii International Conference on System Sciences. Los Alamitos, CA: IEEE Computer Society, 2007 (available at www2. computer.org/plugins/dl/pdf/proceedings/hicss/2007/2755/00/27550250b.pdf?template= $1 \& \operatorname{loginState}=1 \&$ userData=anonymous-IP\%253A\%253A127.0.0.1).

107. Schunk, D.H. Learning Theories: An Educational Perspective, 4th ed. Upper Saddle River, NJ: Pearson/Merrill/Prentice Hall, 2004.

108. Scott, C.R. Communication technology and group communication. In L.R. Frey (ed.), The Handbook of Group Communication Theory and Research. London: Sage, 1999, pp. 432-472.

109. Sein, M.K.; Bostrom, R.P.; and Olfman, L. Rethinking end-user training strategy: Applying hierarchical knowledge-level model. Journal of End User Computing, 11, 1 (1999), 32-39.

110. Silver, M.S. Systems that Support Decision Makers: Description and Analysis. New York: Wiley, 1991.

111. Straub, D.; Limayem, M.; and Karahanna-Evaristo, E. Measuring system usage-Implications for IS theory testing. Management Science, 41, 8 (1995), 1328-1342.

112. Taylor, C. To follow a rule .... In C. Calhoun, E. LiPuma, and M. Postone (eds.), Bourdieu: Critical Perspectives. Chicago: University of Chicago Press, 1993, pp. 45-60.

113. Te'eni, D. Review: A cognitive-affective model of organizational communication for designing IT. MIS Quarterly, 25, 2 (2001), 251-312.

114. Thomas, D.M., and Bostrom, R.P. The role of a shared mental model of collaboration technology in facilitating knowledge work in virtual teams. In R.H. Sprague Jr. (ed.), Proceedings of the Fortieth Annual Hawaii International Conference on System Sciences. Los Alamitos, CA: IEEE Press, 2007 (available at www2.computer.org/plugins/dl/pdf/ proceedings/hicss/2007/2755/00/27550037a.pdf?template $=1 \&$ loginState $=1 \&$ userData $=$ anonymous-IP\%253A\%253A127.0.0.1).

115. Thomas, D.M., and Bostrom, R.P. Building trust and cooperation through technology adaptation in virtual teams: Empirical field evidence. Information Systems Management, 25, 1 (2008), 45-56.

116. Thomas, D.M.; Bostrom, R.P.; and Gouge, M. Making knowledge work successful in virtual teams via technology facilitation. Communications of the ACM, 50, 11 (2007), 85-90.

117. Timbrell, G.; Delaney, P.; Chan, T.; Yue, A.; and Gable, G. A structurationist review 
of knowledge management theories. In W. King and R. Torkzadeh (eds.), Proceedings of the Twenty-Sixth International Conference on Information Systems. Atlanta: Association for Information Systems, 2005, pp. 247-259.

118. Trist, E., and Murray, H. (eds.). The Social Engagement of Social Science: A Tavistock Anthology-Volume II: The Socio-Technical Perspective. Philadelphia: University of Pennsylvania Press, 1990.

119. Tyre, M.J., and Orlikowski, W.J. Windows of opportunity-Temporal patterns of technological adaptation in organizations. Organization Science, 5, 1 (1994), 98-118.

120. Uto, S. Constructics: A Methodology of Theory Construction. Lanham, MD: University Press of America, 2005.

121. Venkatesh, V.; Morris, M.G.; Davis, G.B.; and Davis, F.D. User acceptance of information technology: Toward a unified view. MIS Quarterly, 27, 3 (2003), 425-478.

122. Vreede, G.-J. de, and de Brujin, H. Exploring the boundaries of successful GSS application: Supporting inter-organizational policy networks. DATABASE, 30, 3-4 (1999), 111-130.

123. Vreede, G.-J. de; Jones, N.; and Mgaya, R.J. Exploring the application and acceptance of group support systems in Africa. Journal of Management Information Systems, 15, 3 (Winter 1998-99), 197-234.

124. Walsham, G., and Han, C.-K. Structuration theory and information systems research. Journal of Applied Systems Analysis, 18 (1991), 77-85.

125. Webster, J., and Hackley, P. Teaching effectiveness in technology-mediated distance learning. Academy of Management Journal, 40, 6 (1997), 1282-1309.

126. Webster, J., and Watson, R.T. Analyzing the past to prepare for the future: Writing a literature review. MIS Quarterly, 26, 2 (2002), xiii-xxiii.

127. Whetten, D.A. What constitutes a theoretical contribution? Academy of Management Review, 14, 4 (1989), 490-495.

128. Woolgar, S., and Grint, K. Computers and the transformation of social analysis. Science, Technology, \& Human Values, 16, 3 (1991), 368-378.

129. Yates, J., and Orlikowski, W.J. Genres of organizational communication: A structurational approach to studying communication and media. Academy of Management Review, 17, 2 (1992), 299-326.

130. Zhang, D.; Zhao, J.L.; Zhou, L.; and Nunamaker, J.F., Jr. Can e-learning replace classroom learning. Communications of the ACM, 47, 5 (2004), 75-79.

131. Zhao, S. Metatheory, metamethod, meta-data-analysis: What, why, and how? Sociological Perspectives, 34, 3 (1991), 377-390.

132. Zigurs, I., and Buckland, B.K. A theory of task/technology fit and group support systems effectiveness. MIS Quarterly, 22, 3 (1998), 313-334.

133. Zigurs, I., and Munkvold, B.E. Collaboration technologies, tasks, and contexts: Evolution and Opportunity. In P. Zhang and D. Galletta (eds.), Human-Computer Interaction in Management Information Systems: Applications, Advances in Management Information Systems, vol. 6. Armonk, NY: M.E. Sharpe, 2006, pp. 143-169. 
Appendix: IS Structural Dimensions Examples

\begin{tabular}{ll} 
Structural dimension & Reference \\
\hline Restrictiveness & Silver [110] \\
Sophistication & DeSanctis and Gallupe [25] \\
Structure & Poole and DeSanctis [93] \\
Control & Poole and DeSanctis [93] \\
Synchronicity & Poole and DeSanctis [93] \\
Comprehensiveness & Cats-Baril and Huber [15] \\
Self-directivity/learner control & Zhang et al. [130] \\
Flexibility & Zhang et al. [130] \\
Just-in-time knowledge & Zhang et al. [130] \\
Personalization & Zhang et al. [130] \\
Interactivity of feedback & Piccoli et al. [91] \\
Richness & Webster and Hackley [125] \\
Telepresence & Papa et al. [89] \\
\hline
\end{tabular}


Copyright of Journal of Management Information Systems is the property of M.E. Sharpe Inc. and its content may not be copied or emailed to multiple sites or posted to a listserv without the copyright holder's express written permission. However, users may print, download, or email articles for individual use. 